\title{
Mobile-Assisted Language Learning
}

\author{
Tayebeh Mosavi Miangah ${ }^{1}$ and Amin Nezarat ${ }^{2}$ \\ ${ }^{1}$ English Language Department, Payame Noor University, Yazd, Iran \\ mosavit@pnu.ac.ir \\ ${ }^{2}$ Information Technology Department, Shiraz University, Shiraz, Iran \\ aminnezarategmail.com
}

\begin{abstract}
The main characteristics of mobile learning (m-learning) are recognized as the potential for learning process to be personalized, spontaneous, informal and ubiquitous. Although learning through mobile phones may take longer time compared to computers, the learners feel a greater sense of freedom of time and place, so that they can take the advantage of spare time to learn a second language when and where they are.

Mobile-Assisted Language Learning (MALL) deals with the use of mobile technology in language learning. In contrast to classroom learning, in MALL there is no need for the learners to sit in a classroom or at a computer to get learning materials. In fact, MALL can be considered an ideal solution to language learning barriers in terms of time and place.

In this paper by looking at some applications of m-learning as well as some examples across various aspects of it, we observe the advantages and disadvantages derived from using mobile technologies for students as well as professionals. Here, it has been tried to demonstrate the benefits of using mobile phones in learning English as a second language. Areas of mobile-based language learning discussed in this paper are vocabulary, listening, grammar, phonetics, and reading comprehension.
\end{abstract}

\section{KEYWORDS}

e-learning, mobile-assisted language learning, mobile technology, second language learning, wireless communication

\section{INTRODUCTION}

In the world that emerging technology-supported devices are rapidly growing, wireless communication technology is not an exception in this respect. As mobile phones with high capabilities extend into all areas of human life, it is expected that this wireless computing device soon becomes accessible for all urban and rural areas of each country. So, widespread access to such an inexpensive and sophisticated device has rather changed the landscape of e-learning in many ways. In fact, mobile learning can be considered as the next generation of e-learning [13]. Mobile devices are not substitute for existing learning devices, but they serve as extension for learning in new environment having new capabilities, though, not all learning content and activities are appropriate for mobile devices [3]. Mobile learning is characterized by its potential for learning to be spontaneous, informal, personalized and ubiquitous. Such learning is reinforced when people encounter shortage of free time as the result of working longer hours. In 
such an environment, busy people tend to use portable devices to learn new materials rather than taking time for traditional classroom-based courses.

There are some factors having key roles in the use of mobile devices in learning environments. Physical characteristics of a mobile phone such as its size and weight as well as input and output capabilities such as keypad vs. touchpad and screen size and audio functions are among the factors which should be assessed in this respect. The learner skills and his/her prior knowledge and experience with mobile devices for learning, as well as the learner's attitude towards the learning through mobile phone play a crucial role in the output quality of such a mobile-based tasks [7].

In this study we try to investigate the way of effective learning through mobile technologies, a shift from teacher-led learning to student-led one, via m-learning. The possibilities of learning a second language in a mobile-based environment are demonstrated accompanying by some examples of learning via mobile devices. Here, it has been tried to show the benefits of using mobile phones in learning English as a second language. Areas of mobile-based language learning discussed in this paper are vocabulary, listening, grammar, phonetics, and reading comprehension.

\section{Mobile Learning, Advantages ANd Disadvantages}

Among all modern communication devices, mobile phones are the most powerful communication medium even richer than email or chat as it can act as a learning device despite its technical limitations. With such a learning device the learner controls the learning process and progress in his/her own space based on his/her cognitive state.

Learning through the computer or e-learning enables the learners to learn in a non-classroom environment when they are at home in front of their personal computers online or offline. However, learning through the mobile phone or m-learning provides the learners with the opportunity to learn when they are in the bus, outside or at work doing their part-time jobs. In fact, they can learn every time and everywhere they are.

Two main characteristics of mobile devices are portability and connectivity. As for connectivity, designing the mobile system must have capability of being connected and communicated with the learning website using the wireless network of the device to access learning material ubiquitously including short message service (SMS) and mobile e-mail. Portability enables learners to move mobile devices and bring learning materials [4].

Klopfer and his colleagues state the following properties of mobile devices: 1) portability: such devices can be taken to different places due to small size and weight; 2) social interactivity: exchanging data and collaboration with other learners is possible through mobile devices; 3) context sensitivity: the data on the mobile devices can be gathered and responded uniquely to the current location and time; 4) connectivity: mobile devices can be connected to other devices, data collection devices, or a common network by creating a shared network; 5) individuality: activities platform can be customized for individual learner [6].

The widespread influence of the market increased the popularity of the mobile phone, and this fulfills the need of teachers to provide tools and software for the learners in teaching contexts. Moreover, comparing with other wireless devices such as laptop computers, mobile phones are rather inexpensive having functions as Internet browsers available in most devices. With such inexpensive devices accessible to even the poorest areas and having the 
functionalities of e-mail or SMS, it is now possible to transfer information to and from mobile phones between instructors and learners without any difficulty.

Although learning service through mobile devices has some advantages, it has its own constraints as small screen, reading difficulty on such a screen, data storage and multimedia limitations, and the like. Many of the mobile phones are not designed for educational purposes. That is, it is difficult for the learners to use them for the task given by the teachers to be carried out. This is partly due to the initial design of such devices, and partly due to non-existence of such developed mobile phones. However, those devices which are appropriate for specific learning tasks are too expensive for most of the learners to buy. Thus, teachers should be aware of what kinds of tools learners have, and then set to chose or adapt resources compatible to such tools [9].

In an experiment, Stockwell demonstrated that the learners found the activities take too long to complete on the mobile devices, and consequently, some of them preferred to use their PCs to do their assigned tasks. In that experiment many learners indicated from the outset that they did not intend to use the mobile phones for doing their tasks because of the cost of Internet access, the screen size, and the keypad [14].

\section{EXAMPLES OF MOBILE LEARNING}

Wireless communication technology are applied to many fields such as GPS navigation, wireless monitoring system as well as learning various materials including learning language skills. Mobile learning can take place either within the classroom or outside it. In the former case, mobile phones possessing appropriate software are very effective in collaborative learning among small groups. Although this type of learning has nothing to do with the mobility property of such devices, it provides the learners with the opportunity of close interaction, conversation, and decision-making among the members of their group due to the specific design of the learning activity on mobile phones. These types of interaction among learners and their physical movement can hardly be achieved when desktop or laptop computers are to be used.

Mobile learning technology is more useful for doing activities outside the classroom. Such activities enable learning to be more directly connected with the real world experiments. Moreover, learning through mobile phones outside the classroom has the advantage of better exploiting the learner's free time; even the students on the move can improve their learning skills [10].

SMS-based learning is another development in the use of wireless technologies in education in which receiving wanted text messages supports learning outside of classroom and helps learners benefit from their teacher's experimentation with mobile technology [10].

Game-based learning is another theme for mobile learning in which learning materials are so designed to be integrated with aspects of physical environment. In such environments, learning activities are facilitated using the mobile technology which serves as a link between the real world of knowledge and the visual world of the game. TimeLab, for instance, is a game about climate change and its effects. Players succeed to get information about the introduction of possible new environmental laws via their mobile devices in different locations as they progress in the game. They will later discuss the results of the game in the classroom [10].

The m-learning games can also be used to teach second language skills such as vocabulary, pronunciation, grammar, listening and reading comprehension and spelling. According to 
Canny, cell phones offer an ideal platform for learning since they are ubiquitous, affordable, compact and wireless [11].

The researchers of the project MILLEE at the university of California (UC Berkeley) concentrated on simple English language skills and designated a series of games that constitute a curriculum equivalent to an ESL course. They tested their cell phone-based learning games in North India. They reported that the game play can produce significant learning benefits, and this type of learning will enhance student's basic skills and provides clues to the sustainability and scalability of their approach Microsoft research program).

\section{MOBILE PHONES}

Many researchers were so interested in MALL approaches that they attempt to provide some strong supports to conduct further studies on this discipline. Today, mobile learning is easily possible by delivery of various learning materials or content to learners through the mobile devices. Various activities related to language learning are supported by mobile devices among which we can name SMS, internet access, camera, audio/video recording, and video messaging (MMS). Different activities supported and performed by various mobile devices depending of the model and facilities of the device have been shown in Appendix 1. [8]

One of the advantages of mobile learning is that collaborative learning is very encourages in this kind of learning. That is, different learners are able exchange their knowledge, skills and attitudes through interaction. Collaborative learning helps the learners to support, motivate and evaluate each other to achieve substantial amounts of learning, the property which is almost absent in other kinds of learning. One can attain a good collaborative approach simply by using a mobile device as an environment for learning, which is, of course, highly dependent of the users than the devices. Devices, in fact, act as pencils and calculators which are the basic equipment in a learning process of a student. What is important, here, is the communication between the learners, as an important factor in language learning is the interaction in the target language [16]

There are different mobile devices in the market compatible to the needs of different users. The basic activities can be performed by many mobile phones. However, for language learning, the cost and technologies related to the mobile devices should be taken into consideration. Such learners can use their customized mobile devices for language learning based on their own abilities. The possible MALL activities and users for some mobile devices has been shown in Appendix 2 [8]

\section{Mobile-Assisted Language Learning (MALL)}

When, in 1973, the mobile devices were invented for the first time, no one ever thought some day they would become an important part of routine life. As soon as the mobile phones became a crucial part of our lives, there felt a need for using them in language learning tasks.

These days mobile devices such as PDAs, phones, and other handheld devices, are used everywhere for doing everything ranging from voice calling to making short message, video chat, listening to audio (Mp3, Mp4, Mpeg), web surfing, shopping, and the like. Apart from these benefits, mobile devices have increasingly grown toward becoming tools for education and language learning, and all its users from teachers or students are getting used to this 
environment to make education as ubiquitous as possible. Moreover, the emerging of internet made open and distance learning a means of receiving education from all parts of the world. In a short period, the attractiveness of distance learning led to the realization that various mobile devices provide a very effective resource for education. This way, many researchers tried to make mobile devices a rich resource for teaching and learning. It was, in fact, a challenging affair to cover learning tasks by a mobile phone [8].

MALL deals with the use of mobile technology in language learning. Students do not always have to study a second language in a classroom. They may have the opportunity to learn it using mobile devices when they desire and where they are. As learning English is considered a main factor for professional success and a criterion for being educated in many communities, providing more convenient environment for people to learn English is one of the strategic educational goals towards improving the students' achievement and supporting differentiation of learning needs.

There are many researches and developments towards the use of wireless technology for different aspects of language learning. In the following lines it has been tried to demonstrate the benefits of using mobile phones in learning English as a second language. Areas of mobile-based language learning are diverse among which the most common ones are vocabulary, listening, grammar, phonetics, reading comprehension, etc.

\subsection{Learning Vocabulary}

The type of activities focusing on vocabulary learning via mobile phone differs from one research project to another, depending on the level of language proficiency of the learners. Sending e-mail or SMS to students is a common way of learning new vocabulary based on the lessons covered in the classroom. In a study Kennedy and Levy gave the learners the option to receive messages covering known words in new contexts through SMS to their mobile phones amounting nine or ten messages per week. The results indicated that the messages were very helpful for learning vocabulary [5].

Similarly, Thornton and Hiuser sent short mini-lessons for learning vocabulary through email to mobile phones of the students three times a day. They used new words in multiple contexts for the learners to infer the meaning. The results showed an improved range of scores on post-tests which were very encouraging [15].

There are other strategies for learning vocabulary via mobile phones. Learners can be provided with some tailored vocabulary practices based on activities performed in the classroom. They are, then, asked to complete them on their mobile phones and send them back to their instructors.

Learning vocabulary can also be accompanied by the pictorial annotation shown on learners' mobile devices for better understanding of new words. In a study conducted by Chen, et al., learners were provided with verbal as well as pictorial annotation for learning English vocabulary. Results of a post-test showed that the pictorial annotation assisted learners with lower verbal and higher visual ability to retain vocabulary [2].

\subsection{Listening Comprehension}

Listening exercises may be considered the first stage in learning a second language. With the advent of the second generation of mobile phones, it is now possible to design a mobile multimedia system for learning listening skills through listening exercises. 
Huang and Sun designed a system composing of two subsystems. A multimedia materials website that uploaded and maintained video materials, and a set of multimedia English listening exercise on the mobile phone for the learners to repeat exercises in English listening in a ubiquitous learning environment. They attempted to implement the mobile multimedia English listening practice system based on capabilities of the mobile technology providing learners download multimedia sound contents from mobile devices, register the learning website, order mobile learning courses and activate reception of learning courses. According to Huang and Sun, mobile multimedia English listening exercise system can enhance learner's English listening abilities to a high degree [4]. It is also possible to design a platform in which learners listen to a text by vocal service on their mobile phones, followed by a listening comprehension quiz based on the text.

\subsection{Learning Grammar}

Grammatical points can be learnt through a specifically designed program installed on mobile devices, in which grammatical rules are taught, followed by multiple-choice activities where learners select the correct answer from the given alternatives. Grammatical exercises can be in the form of 'true-false' or 'fill-in the blanks' which are to be responded by the learners. Grammatical explanations may also be presented to learners via vocal service or short message service.

\subsection{Pronunciation}

The second generation of mobile devices enable their users to access multimedia functions including listening and speaking ones. A good m-learning service should consist of speech facilities for transmitting voice. Having such facilities, the learners may download dictionaries on the PDA1 with sound functions so that they can learn the correct pronunciation of unfamiliar or new words to be able to fulfill their learning needs. Mobile devices with multimedia function give the learners the opportunity to record their own voice. Then, teachers are able to make a better assessment of the students' weaknesses in pronunciation. This way, by enhancing various functions of the system like providing a dictionary for looking up unfamiliar words and their correct phonetic form, the pronunciation as well as speaking skills of the learners can be well improved.

The Praxis learning podcast line is a platform providing a context-driven, social-based, and software-enhanced website for learning foreign languages. It has recently been working to release mobile language learning features for PDAs, smart phones, etc., enabling learners to learn phonetics of a given language in an interaction way using multimedia functions on the mobile phones (Microsoft research program).

The speech aspect of mobile learning is as significant as textual aspect of it, since it enables learners to comfortably speak with a system recording their voice and allowing them to listen back to themselves. Then, they can compare their voice with an ideal pronunciation and make an improvement in this skill [18].

\subsection{Reading Comprehension}

Reading practices help learners to enhance their vocabulary, and vocabulary knowledge, in turn, helps them to promote reading comprehension [2]. Reading activities can be offered to learners either via a well-designed learning course installed on the mobile devices or through SMS sent

1- Personal Digital Assistant like a basic palmtop computer 
to the learners. In either case upon finishing the reading activity, the learners are provided with a reading text function to evaluate their reading comprehension skill.

To offer an effective and flexible learning environment for English learning, Chen and Hsu attempted to present a personalized intelligent mobile learning system known as PIM in which the learners were provided with English news articles based on their reading abilities evaluated by fuzzy item response theory. To promote the reading abilities of English news, the PIM system would automatically discover and retrieve unknown vocabularies of individual learners from the reading English news articles. The experimental results of the study indicated that English news reading learning along with unfamiliar vocabulary learning with self-assessing feedback response are very effective in prompting reading comprehension and reading abilities of the learners [2].

Mobile learning programs in which reading function accompanied by text announcer pronunciation will be more helpful to promote at the same time both reading comprehension and listening comprehension.

\section{ConClusion ANd Further DeVElopMent}

The rising speed of mobile technology is increasing and penetrating all aspects of the lives so that this technology plays a vital role in learning different dimensions of knowledge. Today, a clear shift from teacher-led learning to student-led learning that m-learning allowed causes the students feel using the technology more effective and interesting than before. In fact, we can provide a richer learning environment through mobile phones for our language learners.

Though many researches have been carried out towards MALL technology as a growing field of study in language learning, there are still so many works left to be done and a large amount of information to be uncovered. Moreover, the methods with the help of which mobile device technology can be used to provide a more robust learning environment have to be further improved. The ways through which the barriers of CALL have been removed can help the MALL technology to grow with less effort and cost. Some language skills such as speaking and listening skills as mobile-based activities need some further improvements due to the hardware weaknesses. Mobile-based learning or m-learning faces many challenges, but it has grown in exponentially in spite of all its problems to provide a better environment for language learning.

Mobile learning technology, however, has a rapid pace of development from a teacher-learner text-based approach to a forthcoming multimedia supporting technology. In addition, podcast lectures and digitized audio comments made the online interaction between teachers and learners possible in a more convenient way without any time and space limitations [12].

Although going through language activities on mobile phones may take longer time compared to computers, the learners feel a greater sense of freedom of time and place, so that they can take the advantage of spare time to learn a second language when and where they are. Mobile technology gets learning away from the classroom environment with little or no access to the teacher, though the learning process can hardly be accomplished without a teacher's direction or guidance. As the demand for acquiring a foreign language increases and the people time for more formal, classroom-based, traditional language learning courses decreases, the need felt by busy users for learning a foreign language through MALL will inevitably increases. In other word, MALL can be considered an ideal solution to language learning barriers in terms of time and place. 
According to Yamaguchi, "A computer is better than a mobile phone or handling various types of information such as visual, sound, and textual information, but the mobile phone is superior to a computer in portability. Further, some students do not have their own computers." [17].

There are some limitations in MALL approaches which are hoped to be handled with some future works, since the discipline has high potential for further development and improvement. Enhancing mobile devices with video and voice chat features will make such MALL-based technology more efficient both for the teachers and the students, as the teachers can use voice or video chat to provide their students with learning material and receive their feedback.

Further research and experiments on MALL-based techniques should be carried out for different languages having different properties. Arabic and Persian languages, for example, are written from right to left and Chinese language is written both from right to left and from left to right. As a result, mobile devices need to be so devised to be more compatible with such languages with different orientations, making the scope of these devices usage greater than before.

Appendix 1. MALL Activities by Device, Medium and Communication Route

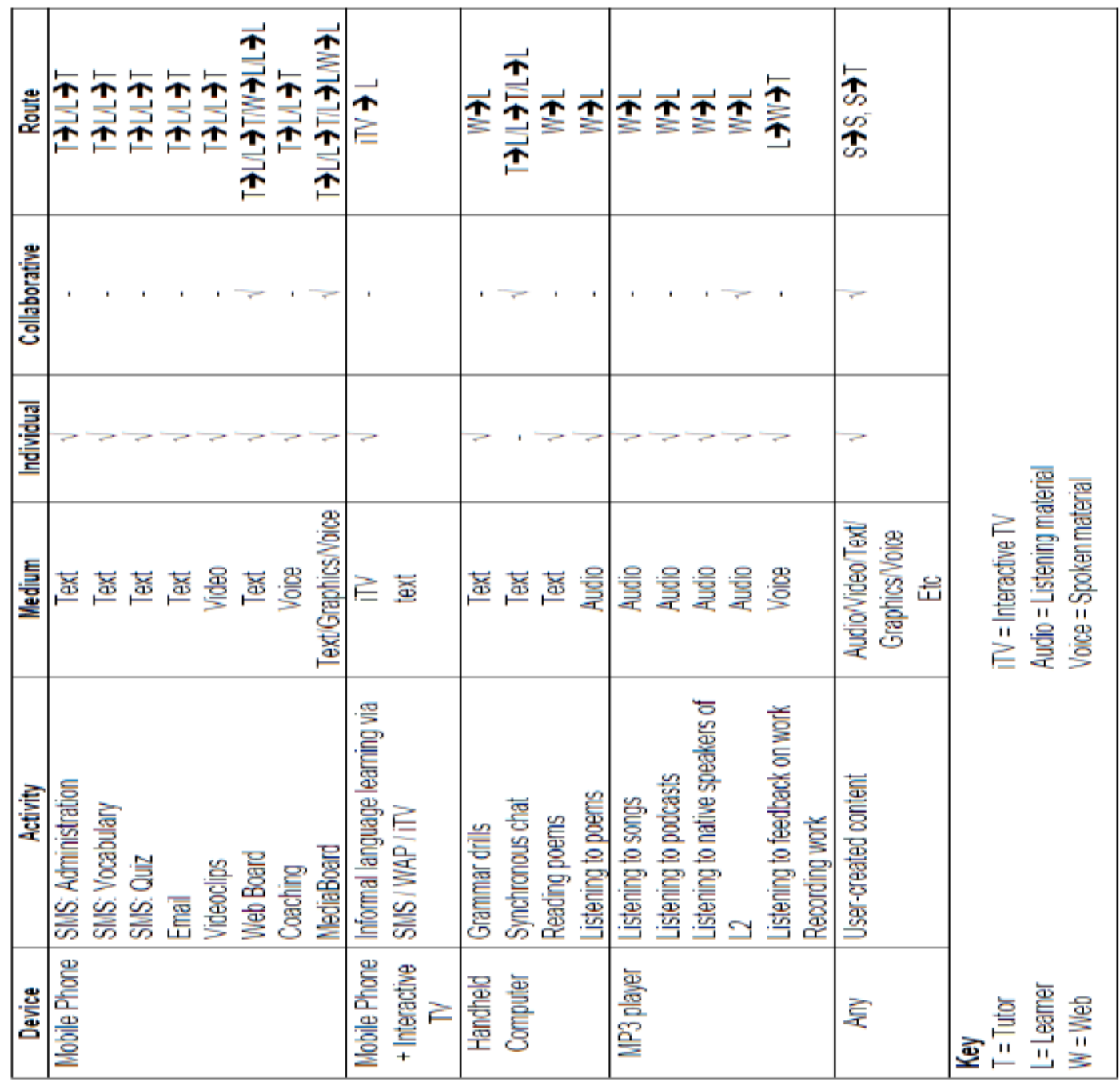


International Journal of Distributed and Parallel Systems (IJDPS) Vol.3, No.1, January 2012

Appendix 2. Possible MALL Activities and Audiences for Low-Tech, Low-Cost Mobile Devices

\begin{tabular}{|c|c|c|}
\hline Learmers could: & Comment & Audience \\
\hline keep an audio record of their sududies in a timely manner & $\begin{array}{l}\text { While text-based reflective logs require learners to make a } \\
\text { conscious effort to key in information, an audio-log allows for } \\
\text { just-in-ime entries that can be made unotonsinely and later } \\
\text { incomporated into a reflective diay. }\end{array}$ & Selfonly \\
\hline $\begin{array}{l}\text { make audio, video and pictorial recordings of activities that } \\
\text { required them to interveur native speakers }\end{array}$ & $\begin{array}{l}\text { Such recordings would give learners access to an archive of } \\
\text { personally mearingful recordings that. might be more } \\
\text { motivating than course materials. They would also have a } \\
\text { record of their own develooment in using } L 2 \text {. }\end{array}$ & Self onlyother leamers \\
\hline $\begin{array}{l}\text { record native speaker to native speaker interaction, to listen } \\
\text { to and reflect on at a later stage, possibly incorporating } \\
\text { these recordings into their own reflective logs or } \\
\text { assignnent outputs }\end{array}$ & $\begin{array}{l}\text { Such recordings would give learners access to an archive of } \\
\text { personally mearingul recordings that. might be more } \\
\text { motivaing than course materials. }\end{array}$ & Self only other learners \\
\hline $\begin{array}{l}\text { archive and or upload recordings.sphotoyraphs svideod ips to } \\
\text { an indwidual reflective blog }\end{array}$ & $\begin{array}{l}\text { This would allow leamers to develop a multimedia blog, } \\
\text { charing their progress through the course. }\end{array}$ & Self onlyitutior \\
\hline upload recordings photographs videocips to a group blog & 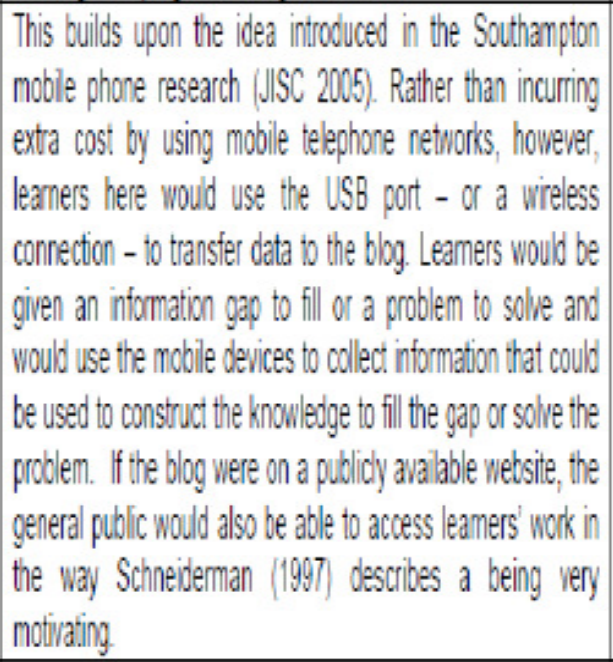 & $\begin{array}{c}\text { Selfiellow } \\
\text { learnerstutori(general } \\
\text { public) }\end{array}$ \\
\hline $\begin{array}{l}\text { keep a record of nev vocabulay items, induding } \\
\text { pronunciation }\end{array}$ & $\begin{array}{l}\text { Leamers could build up a personalised, mutimedia vocabulary } \\
\text { list, possibly also addressing issues such as regional accents } \\
\text { and so on. }\end{array}$ & Selfonly \\
\hline downhoad foreign language MP3 files & $\begin{array}{l}\text { Use the devices' voice recording facilities Isten to content in a } \\
\text { variety of locations }\end{array}$ & Selfonly \\
\hline
\end{tabular}


International Journal of Distributed and Parallel Systems (IJDPS) Vol.3, No.1, January 2012

\section{REFERENCES}

[1] Chen, N. S. S.-W., Hsieh, \& Kinshuk. (2008). "Effects of short-term memory and content representation type on mobile language learning". Language Learning \& Technology, 12(3), pp. 93113. Retrieved from http://llt.msu.edu/vol12num3/chenetal.pdf

[2] Chen, C. M. \& S.-H. Hsu. (2008). "Personalized Intelligent Mobile Learning System for Supporting Effective English Learning". Educational Technology \& Society, 11 (3), pp. 153-180.

[3] Gay, G.; M. Stefanone, M. Grace-Martin, \& H. Hembrooke. (2001) "The effects of wireless computing in collaborative learning environments". International Journal of Human-Computer Interaction, 13(2), pp. 257-276.

[4] Huang, C. and P. Sun. (2010) "Using mobile technologies to support mobile multimedia English listening exercises in daily life". In: The International Conference on Computer and Network Technologies in Education (CNTE 2010), At: http://cnte2010.cs.nhcue.edu.tw/

[5] Kennedy, C. \& M. Levy. (2008). 'L'italiano al telefonino: Using SMS to support beginners' language learning". ReCALL, 20(3), pp. 315-350.

[6] Klopfer, E.; K. Squire, and H. Jenkins. (2002). "Environmental Detectives: PDAs as a window into a virtual simulated world." In: Proceedings of IEEE International Workshop on Wireless and Mobile Technologies in Education. Vaxjo, Sweden: IEEE Computer Society, pp. 95-98

[7] Koole. M. (2009). "A model for framing mobile learning" . In M. Ally (Ed.), Mobile learning: Transforming the delivery of education \& training, pp. 25-47. Athabasca: AU Press.

[8] Kukulska-Hulme A. and L. Shield. (2008). "An Overview of Mobile Assisted Language Learning: Can Mobile Devices Support Collaborative Practice in Speaking and listening?" http://portal.acm.org/citation.cfm?id=1520087, accessed Jul. 2009.

[9] Kukulska-Hulme, A. \& J.Traxler. (Eds.). "Mobile learning: A handbook for educators and trainers". London: Routledge, 2005.

[10] Kukulska-Hulme. A. (2009). "Will mobile learning change language learning?" ReCALL 21(2), pp. $157-165$

[11] Microsoft research program. (2010). At:http://research.microsoft.com/enus/collaboration/papers/berkeley.pdf, accessed Jul. 2010

[12] Oxford R. and J. Oxford. (2009). "Second Language Teaching and Learning in the Next Generation", 2009. http://llt.msu.edu/vol14num1/review1.pdf, accessed Jul. 2010.

[13] Sharples. M. (2000). "The design of personal mobile technologies for lifelong learning". Computers \& Education, 34(3-4), pp. 177-193.

[14] Stockwell. G. (2008). "Investigating learner preparedness for and usage patterns of mobile learning". ReCALL, 20(3), pp. 253-270.

[15] Thornton, P. \& C.Houser. (2005). "Using mobile phones in English education in Japan. Journal of Computer Assisted Learning", 21(3), pp. 217-228. 
International Journal of Distributed and Parallel Systems (IJDPS) Vol.3, No.1, January 2012

[16] Yang Soon. G. (2005). "Technology for Foreign Language Learning". http://www.readingmatrix.com/conference/pp/proceedings/gohyingsoon.pdf, accessed Dec 2010.

[17] Yamaguchi. T. (2005). "Vocabulary Learning with a Mobile Phone". http://llt.msu.edu/vol10num1/emerging/default.html, accessed Jul. 2010.

[18] Yannick. J. (2007). "M-Learning: A pedagogical and technological model for language learning on mobile phones". In: Blended Learning, Joseph Fong, Fu Lee Wang (Eds), 2007, pp. 327-339. 